\title{
Breast Feeding Practices Influences In the Postpartum Period upon Puerperal Woman Health Status at Primary Health Care Centers in Baghdad City
}

\author{
Dr. Rabea Mohsen Ali, $\mathrm{PhD}^{1}$, Sarab Nasr Fadhil, MSc. ${ }^{2}$ \\ ${ }^{1}$ (Professor, Maternal and Neonate Nursing Department, College of Nursing, University of Baghdad) \\ ${ }^{2}$ (Assistant Instructor, Maternal and Neonate Nursing Department, College of Nursing, University of Baghdad)
}

Abstract: The postpartum and postnatal care is important, In particular, the consequences of the effects of culture on the well-being of the mother and the child during this time.

Objective: To identify postpartum breast feeding practices of puerperal women.

Methodology: A descriptive Analytical study was conducted on Non-probability (purposive sample) of (100) puerperal woman who attend Al-bayaa primary health care center in al Karech sector, and Bab Al-Muaddam primary health care center in Al-Rusafa sector for follow up. A questionnaire was used as a tool of data collection for the period $15^{\text {th }}$ March to $30^{\text {th }}$ April. Descriptive statistical analyses were used to analyze the data. Results :The results of the study revealed that (31\%) of women their age range (25-29) years, (45\%) graduated from preparatory school, (56\%) housewives, And about the reproductive information (36\%) primi gravid, (57\%) are ranged between primipara and second birth, (31\%) have abortion, (61\%) have normal vaginal delivery, (36\%) have "episiotomy" with the delivery, and the source of data regarding women practices (43\%) of them the family are the major source, and about the women practices during post-partum period the vast majority of study sample (86\%) use breast feeding,(32\%) use artificial feeding in child nutrition. The causes related to that (32\%) of study sample think that mother milk don't enough, and (23\%) of them are think that the breast feeding restrict her activity, (82\%) of study sample use cotton compresses when there is leakage of milk from the breast. Conclusions: the study concluded that the breast feeding practices in post- partum period are popular among the participants. Family play a major role in reinforcing these practice

Recommendations: The study recommended undertaking education program to rise awareness of the women about wrong practices in order to correct it. Discharge guide program should be carried out for puerperal women to instruct.

Keywords: Breast feeding, Practices, Post -partum, puerperal.

\section{Introduction}

The post-partum period is a time of readjustment and adaptation for the entire childbearing family but especially for the mother. The women experience a variety of responses as she adjusts to a new family member, postpartum discomforts, changes in her body image, and the reality that she is no longer pregnant ${ }^{[1]}$. Post-partum period is one of the most important stages for the mother-child dichotomy, and has been influenced by multiple cultural beliefs and practices transmitted from generation to generation ${ }^{[2]}$. These beliefs are associated with unhealthy practices, during the postpartum period then maternal and infant mortality and morbidity are known to be affected ${ }^{[3]}$.

\section{Methodology}

A descriptive Analytical study was carried out upon puerperal woman who attend to primary health care center for follow up. Study implemented for the period $15^{\text {th }}$ March to $30^{\text {th }}$ April 2015. Data collection will be gathered by questionnaire format, and interview with women. The research study was conducted in two primary health care centers at Baghdad City which include two primary health care centers Al-bayaa primary health care center in al Karech sector , and Bab Al-Muaddam primary health care center in Al- Rusafa sector. Puerperal women who attend to primary health care center for follow up were selected as study sample. A questionnaire was used as a tool of data collection to fulfill with objective of the study and consisted of four parts, including demographic, reproductive characteristics, source of women knowledge, and breast feeding practices of puerperal women. Descriptive statistical analyses were used to analyze the data. 


\section{Results}

Table (1): Distribution of (100) Puerperal Woman According to Socio-Demographical Characteristics in Study Sample

\begin{tabular}{|c|c|c|c|}
\hline Variables & Groups & Freq. & $\%$ \\
\hline \multirow[t]{6}{*}{ Age Groups (Per Years) } & $<20$ & 15 & $15 \%$ \\
\hline & $20-24$ & 23 & $23 \%$ \\
\hline & $25-29$ & 31 & $31 \%$ \\
\hline & $30-34$ & 18 & $18 \%$ \\
\hline & $35-39$ & 11 & $11 \%$ \\
\hline & 40 and more & 2 & $2 \%$ \\
\hline \multirow[t]{6}{*}{ Educational level - wife } & Illiterate & $\mathbf{1}$ & $1 \%$ \\
\hline & Reads and writes & 7 & $7 \%$ \\
\hline & Primary & 18 & $18 \%$ \\
\hline & Intermediate & 19 & $19 \%$ \\
\hline & Preparatory & 45 & $45 \%$ \\
\hline & Institute, College or above & 10 & $10 \%$ \\
\hline \multirow[t]{4}{*}{ Occupational Status of Wife } & Housewife & 56 & $56 \%$ \\
\hline & Employee & 34 & $34 \%$ \\
\hline & Student & 10 & $10 \%$ \\
\hline & Free Jobs & 10 & $10 \%$ \\
\hline \multirow[t]{3}{*}{ Residential Environment } & Urban & 73 & $73 \%$ \\
\hline & Rural & 8 & $8 \%$ \\
\hline & Sub urban & 19 & $19 \%$ \\
\hline \multirow[t]{3}{*}{ Family type } & Extended & 55 & $55 \%$ \\
\hline & Nuclear & 45 & $45 \%$ \\
\hline & Other & $\mathbf{0}$ & $0 \%$ \\
\hline
\end{tabular}

Freq. =Frequency $\%=$ percentage

Table (1) shows that the highest percentage $(31 \%)$ of study sample was at age group $(25-29)$ years, $(45 \%)$ of study sample was graduated from preparatory schools, $(56 \%)$ of study sample work were housewives, $(73 \%)$ of them resident environment is Urban area, and finally the highest percentage(55\%) are from Extended family

Table (2): Distribution of Reproductive Parameters of (100) Puerperal Women

\begin{tabular}{|c|c|c|c|}
\hline Reproductive Parameters & Groups & Freq. & Percent \\
\hline \multirow{4}{*}{$\begin{array}{l}\text { Gravida } \\
\text { (no .of pregnancy ) }\end{array}$} & Primi gravida & 28 & $28 \%$ \\
\hline & $2-3$ & 36 & $36 \%$ \\
\hline & 4-5 & 26 & $26 \%$ \\
\hline & $6+$ & 10 & $10 \%$ \\
\hline \multirow{3}{*}{$\begin{array}{l}\text { Para } \\
\text { (No. of birth ) }\end{array}$} & $1-2$ & 57 & $57 \%$ \\
\hline & 3-4 & 31 & $31 \%$ \\
\hline & $5+$ & 12 & $12 \%$ \\
\hline \multirow[t]{4}{*}{ Abortions } & None & 64 & $64 \%$ \\
\hline & Previous 1 & 31 & $31 \%$ \\
\hline & Previous 2 & 4 & $4 \%$ \\
\hline & Previous 3 & 1 & $1 \%$ \\
\hline \multirow[t]{2}{*}{ Type of delivery } & Normal vaginal delivery & 61 & $61 \%$ \\
\hline & Cesarean section & 39 & $39 \%$ \\
\hline \multirow{2}{*}{ If it is Normal it is with episiotomy } & Yes & 36 & $36 \%$ \\
\hline & No & 25 & $25 \%$ \\
\hline
\end{tabular}

Table (2) shows that (36\%) of study sample is primi gravid, (57\%) of study sample are ranged between primipara and second birth. $(31 \%)$ of the study sample have abortion. the highest percentage of delivery are recorded at normal vaginal delivery, and they are accounted (61\%). In addition to that, (36\%) percentage of these women reported have "episiotomy" with their delivery.

Table (3): Distribution of Source of Information for (100) puerperal Women

\begin{tabular}{|l|l|l|}
\hline Variable & Percent & Freq. \\
\hline Midwife & 1 & $1 \%$ \\
\hline Visual and auditory & Non & $0 \%$ \\
\hline Primary health center & 20 & $20 \%$ \\
\hline Family & 43 & $\mathbf{4 3 \%}$ \\
\hline Friend & 1 & $1 \%$ \\
\hline Husbands' family & 25 & $25 \%$ \\
\hline Doctor & 10 & $10 \%$ \\
\hline
\end{tabular}


Table (3) show that the highest percentage of the study sample their source of information about practices during post- partum period are from family and they are accounted (43\%), and (25\%) from husbands family, (20\%) from Primary Health Center, (10\%) from Doctors ,(1\%) from Midwife and Friends, and finally none of them have information from Visual and auditory source.

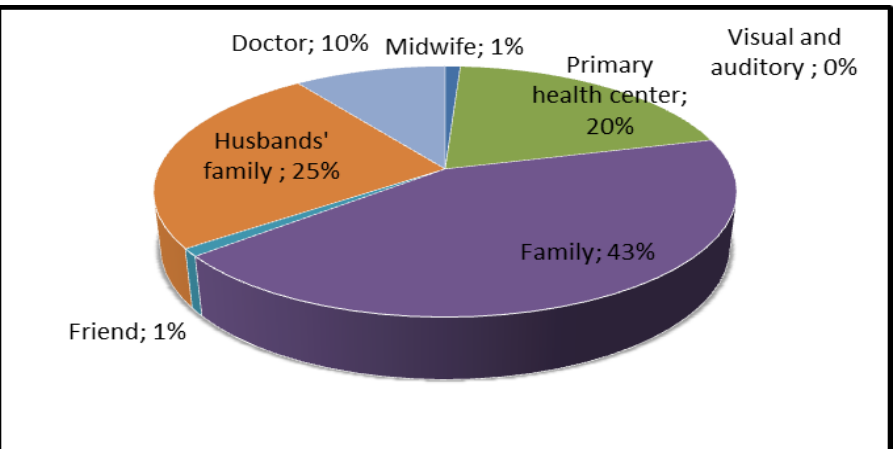

Figure (1): Pie Chart for the Source of Information For the Studied Sample

Table (4): Distribution of (100) Puerperal Women according to Breast Feeding practices

\begin{tabular}{|c|c|c|c|c|c|}
\hline NO. & Breast Feeding Practices & Groups & $\mathbf{F}$ & $\%$ & No \\
\hline \multirow[t]{2}{*}{1.} & \multirow[t]{2}{*}{ The use of breast feeding in child nutrition } & Yes & 86 & $86 \%$ & \multirow[t]{2}{*}{100} \\
\hline & & No & 14 & $14 \%$ & \\
\hline \multicolumn{6}{|c|}{ If the answer Yes why } \\
\hline \multirow[t]{2}{*}{1.1} & \multirow[t]{2}{*}{ Because the mother milk easy to digestion } & Yes & 78 & $\mathbf{7 8 \%}$ & \multirow[t]{2}{*}{86} \\
\hline & & No & 8 & $8 \%$ & \\
\hline \multirow[t]{2}{*}{1.2} & \multirow[t]{2}{*}{ Because it provide food for whole child } & Yes & 80 & $\mathbf{8 0 \%}$ & \multirow[t]{2}{*}{86} \\
\hline & & No & 6 & $6 \%$ & \\
\hline \multirow[t]{2}{*}{1.3} & \multirow[t]{2}{*}{ Breast feeding reduce disease of breast cancer } & Yes & 75 & $75 \%$ & \multirow[t]{2}{*}{86} \\
\hline & & No & 11 & $11 \%$ & \\
\hline \multirow[t]{2}{*}{1.4} & \multirow[t]{2}{*}{ Breast feeding it help in contraction after birth } & Yes & 75 & $75 \%$ & \multirow[t]{2}{*}{86} \\
\hline & & No & 11 & $11 \%$ & \\
\hline \multirow[t]{2}{*}{1.5} & \multirow[t]{2}{*}{ Because the mother milk gives immunity to the child } & Yes & 83 & $\mathbf{8 3 \%}$ & \multirow[t]{2}{*}{86} \\
\hline & & No & 3 & $3 \%$ & \\
\hline \multirow[t]{2}{*}{1.6} & \multirow[t]{2}{*}{ Economic factor } & Yes & 48 & $48 \%$ & \multirow[t]{2}{*}{86} \\
\hline & & No & 38 & $38 \%$ & \\
\hline \multirow[t]{2}{*}{1.7} & \multirow[t]{2}{*}{ Other causes } & Yes & 27 & $27 \%$ & \multirow[t]{2}{*}{86} \\
\hline & & No & 59 & $59 \%$ & \\
\hline \multirow[t]{2}{*}{2.} & \multirow[t]{2}{*}{ The use of artificial feeding } & Yes & 39 & $39 \%$ & 100 \\
\hline & & No & 61 & $61 \%$ & \\
\hline Whe & answer is Yes why & & & & \\
\hline 2.1 & Because mother milk not enough for feeding the baby & Yes & 32 & $32 \%$ & 39 \\
\hline & & No & 7 & $7 \%$ & \\
\hline 2.2 & To maintain the size of the breast & Yes & 2 & $2 \%$ & 39 \\
\hline & & No & 37 & $37 \%$ & \\
\hline 2.3 & The breast feeding increased body weight & Yes & 2 & $2 \%$ & 39 \\
\hline & & No & 37 & $37 \%$ & \\
\hline 2.4 & Breast feeding take all my time & Yes & 17 & $17 \%$ & 39 \\
\hline & & No & 22 & $22 \%$ & \\
\hline 2.5 & Breast feeding increased the pain & Yes & 17 & $17 \%$ & 39 \\
\hline & & No & 22 & $22 \%$ & \\
\hline 2.6 & Breast feeding make restrict my activities & Yes & 23 & $23 \%$ & 39 \\
\hline & & No & 16 & $16 \%$ & \\
\hline 2.7 & For other causes & Yes & 13 & $13 \%$ & 39 \\
\hline & & No & 26 & $26 \%$ & \\
\hline 3 . & Wash the breast with warm water before and after each & Yes & 70 & $\mathbf{7 0 \%}$ & 100 \\
\hline & feeding & No & 30 & $30 \%$ & \\
\hline 4 . & Use cotton compresses and other when there is a & Yes & 82 & $82 \%$ & 100 \\
\hline & leakage of milk from the breast & No & 18 & $18 \%$ & \\
\hline
\end{tabular}

According to the use of breast feeding. Table (4) show that the majority of the study sample (86\%) are use breast feeding and the causes related to that $(83 \%)$ beliefs that mother milk gives immunity to the child, $(80 \%)$ provide food for whole child,(78\%) mother milk easy to digest, and (75\%) breast feeding reduce disease of breast cancer also help in contraction after birth. According to use of artificial feeding the causes related to that $(32 \%)$ of study sample think that mother milk not enough for child feeding, and $(23 \%)$ of them think that the breast feeding restrict their activity. And according to wash breast with warm water before and after 
each feeding (70\%) of the them do it. And finally (82\%) of study sample use cotton compresses and other when there is a leakage of milk from the breast.

\section{Discussion}

Part I :- Discussion of the Woman's Socio Demographic Characteristic:(Table 1)

The result of present study present that the highest percentage (31\%) of study sample was at the age ranged $(25-29)$ yrs., while the lowest percentage $(2 \%)$ of them at age group (40 years and more), $(45 \%)$ at preparatory levels of education , (56\%) are "Housewives", and. (73\%) of them their residential environment was urban, and finally the highest percentage of the study sample lived in "Extended families", and they are accounted $(55 \%)$.

This finding in agreement with the studies assessed that" mothers' perspectives on the quality of postpartum care and they found that the mean age of mothers was 28 years (range 20-38). In relation to the educational level, most of the study sample was educated which will help them to be able to identify their health needs and expectations during post -partum period. In addition, education is a mean that enables women to gain access of knowledge and to control many events in their life. However, more than three quarters of women were housewives while slightly less than one fifth of them were worker. This result insisted the need for complete post -partum health advices for these women because exposure to work outside the home gives women better chances of contact with a more experienced persons and to acquire valuable health and social information. In addition, Three quarters of the women were living in rural areas while the rest were living in urban areas .This reflected women's needs for more health advices and extension of postpartum care services to the community where mothers are receiving care during home visits" ${ }^{(4)}$.

Women who had childbirth preparation and expectations for labor, met a higher level of education and employment, had higher global satisfaction with the childbirth experience ${ }^{(5)}$

\section{Part II:- Discussion of the Woman's Reproductive Parameters:-}

Table (2) shows that the highest percentage of the sample is reported at primi gravid, and they are accounted $(36.0 \%)$, and $(57 \%)$ are ranged between primipara and second birth. $(31 \%)$ are reported at " have abortion", and the highest percentage of delivery are recorded at normal vaginal delivery, and they are accounted (61\%). In addition to that $(36 \%)$, of these women reported have "episiotomy" with their delivery.

This result in agreement with the studies which reported that that more than one half of the women had first para while This reflects women's needs for more support and assistance with baby care and their own personal care. Also first para women experience certain physical health problems in the postpartum period that may affect their future health condition and the health of their children. Moreover, the study revealed that more than one half of the women had spontaneous vaginal deliveries with episiotomies which reflect women's needs to perineal care and to health education about self perineal care ${ }^{(6)}$. Also this result was in agreement with study which found that all the mothers had their babies in the hospital and half of them underwent normal delivery and the other half delivered through caesarean section ${ }^{(4)}$.

\section{Part III:- Discussion of the Woman's Source of Information}

Table (3) show that the highest percentage of the study sample their source of information about practices during post- partum period are from family and they are accounted (43\%), and (25\%) from husbands family, $(20 \%)$ from Primary Health Center, $(10 \%)$ from Doctors , $(1 \%)$ from Midwife and Friends, and finally none of them have information from Visual and auditory source.

It is evident that family members play an important roles on woman's practices as reported by most of the women. These results are congruent with results assessed that practices mainly came from mother in-law and mother ${ }^{(7)}$.

\section{Part IV:- Breast Feeding practices of Puerperal Women}

The postpartum period is a very special phase in the life of a woman. Her body needs to heal and recover from pregnancy and childbirth, a good postpartum care during the puerperal period is very important for her health. Several studies indicated that the incidences of postpartum health problems are high and these problems maybe have relation to traditional and unscientific behavior practices in the postpartum period ${ }^{(8)}$. The post- partum duration consists of variety of practices such as diet, hygiene and healing activities ,breast feeding, etc.

According to the use of breast feeding. Table (4) show that the majority of the study sample (86\%) are use breast feeding and the causes related to that (83\%) beliefs that mother milk gives immunity to the child,(80\%) provide food for whole child,(78\%) mother milk easy to digest, and (75\%) due to that the breast feeding reduce disease of breast cancer also help in contraction after birth, 
Breast milk is the most complete and wholesome nutrition for a newborn. It is also cost-effective, disease-preventing and health-promoting. Despite various advantages of breastfeeding, rates of breastfeeding globally decline rapidly in the first four to eight weeks postpartum ${ }^{(9-11)}$.

Many women either do not breastfeed or breastfeed for only a short duration, or start breastfeeding late the factors known to affect breastfeeding practice include socioeconomic status, maternal education and employment, prenatal intention, maternal attitude and confidence, ethnicity, a shift from a rural to an urban environment (residence) and to nuclear families, emulating Western lifestyles ${ }^{(12 \& 13)}$. Most women who discontinue breastfeeding early do so because of perceived difficulties such as lack of milk, unsuccessful breast attachment, their baby being unable to suckle, leakage, pain and so on ${ }^{(14)}$.

The American Academy of Family Physicians (AAFP) and the American College of Obstetricians and Gynecologists (ACOG). Infants who are breastfed experience nutritional and developmental advantages that enhance their health throughout their lives. The choice to breastfeed conveys health benefits to the mother as well. Breastfeeding also imparts economic benefits for families as well as savings for our society ${ }^{(15)}$.

WHO and UNICEF launched the Baby-Friendly Hospital Initiative (BFHI) in 1992, to strengthen maternity practices to support breastfeeding. The BFHI contributes to improving the establishment of exclusive breastfeeding worldwide and, coupled with support throughout the health system, can help mothers sustain exclusive breastfeeding ${ }^{(9)}$.

Also the present study show that (32\%) of study sample use artificial feeding the causes related to that they think that mother milk not enough for child feeding, and (23\%) think that the breast feeding restrict my activity, (70\%) wash breast with warm water before and after each feeding, and finally (82\%) of study sample use cotton compresses and other when there is a leakage of milk from the breast.

However the results of the present study are congruent with the study which finding that more than one third of women had no intension to breast feed their babies. Women believed that they have problem in milk production and breast feeding increases breast size and body weight ${ }^{(2)}$.

\section{Conclusion}

The study concluded that the breast feeding practices in post- partum period are popular among the participants. Family play a major role in reinforcing these practice

\section{Recommendations}

The study recommended undertaking education program to raise awareness of the women about wrong practices in order to correct it . Discharge guide program should be carried out for puerperal women to instruct.

\section{References}

[1]. American Academy of Pediatric ; Policy statement: Breast feeding and the use of Human Milk, Pediatrics, 2005, 115(2), 496-506

[2]. Mansour S.Lamadah; Postpartum Traditional Beliefs and Practices among Women in Makah AL Mukkaramah, KSA. Life Sci J., 2013,10(2),PP:838-847.

[3]. Particia A. Wiel and Marcia L. London, and Michele R. Davidson; Contemporary Maternal -Newborn Nursing Care, $6^{\text {th }}$ edition, 2006, pp.: 788 .

[4]. Lomoro O.,Ehiri E.,Qian X., and TangL.,Mothers' perspectives on the quality of postpartum care in Central Shanghai, China, Oxford Journal, Int. Journal for quality in Health Care,2002,14(5),pp:393-401.

[5]. Goodman P., Mackey M.,AND Tavakoli A., Factors related to childbirth satisfaction, Journal of Advanced Nursing ,April,2004,46(2) pp:212-219.

[6]. Mohamed H. Abed El-Azim, El Ngger Nahed, and Lamadah Sahar Mansour: Women' perspectives regarding the quality of postpartum nursing care in Ain Shams Maternity Hospital- Cairo, Egypt Journal of American Science, 2012;8(2),pp:366-377. http://www.americanscience.org

[7]. Nian Liu, Limei Mao, Xiufa Sun , Liegang Liu, Banghuachen, Qiang Ding: Postpartum practices of puerperal women and their influencing factors in three regions of Hubei, China. BMC Public Health ,2006.,6:274.

[8]. Nian Liu, Limei Mao, Xiufa Sun, Liegang Liu, Banghuachen, Qiang Ding: the effect of health and nutrition education intervention on women's postpartum beliefs and practices: a randomized controlled trial BMC Public Health, 2009,45.

[9]. WHO/UNICEF: Innocent declaration on the protection, promotion, and support of breastfeeding. In WHO/UNICEF, Breastfeeding in the 1990's: A global initiative meeting in Florence, Italy and New York. Geneva, Switzerland: WHO/UNICEF; 1990.

[10]. Rasheed S, Siddiqui I, Baig LA: Decline in breastfeeding, who is to be blamed A study of knowledge, attitude and practice of breastfeeding amongst nurses. J Pak Med Assoc, 50:8-11, 2000.

[11]. Barber CM, Abernathy T, Steinmetz B, Charlebois J: Using a breastfeeding prevalence survey to identify a population for targeted programs. Can J Public Health, 88:242-245, 1997.

[12]. Ergenekon-Ozelci P, Elmaci N, Ertem M, Saka G: Breastfeeding beliefs and practices among migrant mothers in slums of Diyarbakir, Turkey. Eur J Public Health, 16:143-148, 2006.

[13]. James D, Jackson R, Probart C: Factors associated with breastfeeding prevalence and duration amongst international students. J Am Diet Assoc, 94:194-196, 1994.

[14]. Dennis CL: Breastfeeding initiation and duration: a 1990-2000 literature review. J Obstetric Gynecology Neonatal Nursing. 2002, $31: 12-32$.

[15]. Sheila G. J. Clark and Timothy J. Bungum , The Benefits of Breastfeeding: An Introduction for Health Educators, Californian Journal of Health Promotion 2003, 1,(3), PP:158-163. 